\title{
The Balobedu Cultural Activities and Plays Pertinent to Primary School Mathematics Learning
}

\author{
Benjamin Tatira (Corresponding Author) \\ Mokutu Secondary School \\ P O Box 253, Molototsi 0827, Republic of South Africa \\ E-mail: bentatira@yahoo.com \\ Lillias Hamufari Natsai Mutambara \\ Mathematics Department, Bindura University of Science Education \\ P Bag 1020, Bindura, Zimbabwe \\ E-mail:1hnmutambara@yahoo.co.uk \\ Conilius J. Chagwiza \\ Mathematics Department, Bindura University of Science Education \\ P Bag 1020, Bindura, Zimbabwe \\ E-mail: cjchagwiza@gmail.com
}

Received: February 11, 2011 Accepted: February 23, 2011 Published: February 1, 2012

doi:10.5539/ies.v5n1p78

URL: http://dx.doi.org/10.5539/ies.v5n1p78

\begin{abstract}
For many years, mathematics has been conceived as abstract, a product of western values and divorced from people's everyday lives. This has contributed to the fact that rural and economically disadvantaged communities fail to see the link between school mathematics and their real world experiences. Nonetheless, it goes without question that children tirelessly engage in plays and games at the least available opportunity, and rural communities have well-knitted and immortal cultural activities which possess intricate and diverse mathematical concepts. Herein we report on some of the cultural activities and plays for the Balobedu people of South Africa and their implications for mathematics teaching and learning at primary school level. The researchers have seen the interplay of culture and the development of mathematical concepts worthy studying, as a way of bringing a turnaround in the performance of mathematics in the South African primary schools. Mathematics performance currently is trailing all other subjects of the curriculum, yet it is a key area of knowledge whose competence is necessary for individual and economic development in this modern high-tech world we are living in. Incorporating cultural issues in the methods of teaching in rural areas help learners to perceive that mathematical concepts are not done in isolation, but have a strong connection to their everyday life and therefore worthwhile learning.
\end{abstract}

Keywords: Cultural activities, Games, Plays, Mathematics education, Bolobedu people, Northern Sotho

\section{Introduction}

Nestled amidst the majestic hills of central Mopani District of the Limpopo Province lies the Balobedu kingdom, an African tribe of the Northern Sotho-speaking people. The Balobedu region is roughly surrounded by the Tsonga to the east, the Venda to the north and the Pedi to the south-west. The Balobedu people are said to have originated from present-day Zimbabwe, being the descendants of the historical Mwenemutapa kingdom. The vast region of Bolobedu has a profusion of sovereign villages scattered in its plains and hills alike, each headed by village headman. There are also two small towns within the jurisdiction of Bolobedu, namely, Tzaneen and Modjadjiskloof, as well as large tracts of Boer farms. There are many chiefs in the area, but one notable royalty is that of the rain queen Modjadji, located in Ga-Modjadji, aptly called the head-kraal. Culture and beliefs of the Balobedu are considered a treasure and are meticulously passed down to the next generations by oral traditions and other means.

The Balobedu language Selobedu, a non-Sepedi dialect of the Northern Sotho languages, is spoken nowhere else 
save this rugged area. Through the passage of time, Selobedu has become rather similar to Sepedi, since the latter is the home language done in schools in the greater part of Mopani district. The reason for the above scenario is that Section 6 of the Constitution of the Republic of South Africa (Act 108 of 1996) gives recognition to eleven official languages only, thereby elevating only nine indigenous African languages to official status, (Department of Education (DoE), 2003: 9). Selobedu happens not to be one of the elevated languages. Speaking a mother tongue which is not one of the official languages is often a disadvantage for the learner and it is a reality the Balobedu learners have to contend with, especially that the Department of Education stipulates that the Foundation phase learners must to be taught in their mother tongue (DoE, 2009: 41). Moreover, the Language in Education Policy states that learners are to be taught in their mother tongue for as long as is feasible (DoE, 2008). Speak and listen in Selobedu but read and write in Sepedi, is the uneasy situation facing the Balobedu learners. The aim of the research study is to show that some cultural aspects related to plays and activities of the Balobedu can be incorporated in the learning of mathematics. The use of indigenous plays and activities in mathematics classrooms provides the learners with an opportunity to relate their well-acquainted cultural experiences to mathematical concepts and processes encountered in the classrooms.

South African is referred to as a Rainbow nation, a title which epitomises the country's cultural and ethnic diversity. The population of South Africa is one of the most complex and diverse of all the countries of the world. As such, there is no single culture of the South Africa nation. That being the case, an encompassing research finding on the aggregate population can be misleading if one wishes to understand the cultural activities of the whole country. This has necessitated a disaggregated cultural analysis, which though too small to make statistically valid inferences, may suggest important insights into localised cultural activities. In other words, since the South African population is not homogeneous, any meaningful analysis must involve disaggregation of society into relevant groupings to understand current trends of cultural activities and plays in mathematics education (Reddy, 2006; Fleisch, Shindler and Perry, 2010). The author as an educator in Bolobedu with an interest in building mathematics capacity in the area is keenly interested in the knowledge of the Balobedu cultural activities and plays, and their intercourse to mathematics teaching, learning and attainment (Bush, 2003). Nkopodi and Mosimege (2009) studied mathematical concepts like symmetry, counting, geometrical shapes and proportions identified in the indigenous game of morabaraba among the Pedi and Tswana people of the Limpopo and the North-West provinces respectively because the game was known there and the researchers grew up in those two provinces.

\section{Importance of Mathematics}

Mathematics as a subject is a science to do with computations, measurements and problem-solving to which everyone requires its use in one way or another. People have to count money, beasts, and other things, as well as determine prices, time, areas, boundary fences, costs, and capacity. However, the challenge is that mathematics achievement has been incessantly below expected standards relative to other subjects. This has been exacerbated by the fact that ordinary people fail to see the everyday application of school mathematics, rather, they perceive it as something abstract and cold (Bansilal, James and Naidoo, 2010: 157). Approaches ought to be devised to help link mathematics with everyday life in the classroom, so as to help mathematics concept-formation and drive away the fear of the subject amongst learners. Need for acquisition of mathematical skills cannot be overemphasised, thus we find mathematics together with mathematical literacy are taught in each and every schools in South Africa from Grade R (reception grade) to Grade 12. Even so, research findings have shown that the number of learners registering for mathematics at senior secondary level has been dwindling year by year (Parker, 2011), as learners opt for the relatively easy mathematical literacy subject. Makgato and Mji, (2006) have noted that due to the shortage of mathematics and science teachers in South Africa, some secondary schools do not offer subjects like mathematics and physical sciences at all.

According to Howie (2003: 1), South Africa faces the challenge of providing quality mathematical education for its multicultural society. Consequently, mathematics has been dogged by poor performance since time immemorial (Chikodzi and Nyota, 2010: 4; Makgato and Mji, 2006: 257; Manuel, 2011), relative to other subjects on the curriculum. For example, while the overall the 2009 final Grade 12 (Matric) results were pleasing, results in gateway subjects like mathematics and Physical Science were appalling (Hamlyn, 2010). The general pass rate for the final Grade 12 results did increase from $60.7 \%$ in 2009 to $67.8 \%$ in 2010 , but the mathematics performance merely jumped from $46.0 \%$ in 2009 to $47.4 \%$ in 2010 (Parker, 2011; DoE, 2011: 58). The bulk of poor performances are unremarkably well pronounced in public schools, especially those found in rural areas, as echoed by Hamlyn (2010) who said that lower performance in rural areas remain a challenge for South Africa. In addition, the rural province of Limpopo where this study was conducted is one of the poorest performing provinces in South Africa, with an aggregate below $60 \%$, (DoE, 2010: 41). The medium of instruction, English, has been a contributory factor also, with only $0.4 \%$ and $1.0 \%$ of the population of Limpopo and Mpumalanga respectively being able to 
communicate in English (de Klerk, 2006). This is in part a relic of the apartheid system which was characterised by under-development of human potential to the black populace, to which teaching and learning of mathematics and Science was hardest hit (Makgato and Mji, 2006). Effectually, mathematics literally trails all the others in the national Grade 12 results and in primary school, the recent Annual National Assessment (ANA) revealed that only $28 \%$ of Grade Three learners can do mathematics properly (Waldner, 2011; Erasmus, 2011). The Literacy score for the same group of learners stood at 35\% nationally. In Limpopo province where this study was conducted, literacy and numeracy for Grade Three stood at 30\% and $20 \%$ respectively, well below the national average.

The statistics above indicate that primary-school learners are equally underperforming in Numeracy (mathematics) as are secondary-school ones. The Minister of Basic Education lamented the same when she said learners from primary school arrive at high school not being able to read and write properly; she further said they even lacked systematic knowledge and often found transition to senior grades difficult (Motshekga, 2009). Ideally, these facts are diametric to the notion that the foundation phase of schooling is the most significant phase of any child's school career (Rice, 2010). It is the stage where it is assumed that the foundation to literacy, numeracy and reasoning are laid out, without which success in more advanced grades is a challenge. According to Keet (2010) the 2009 Grade 12 results bore witness that there were problems throughout the education system, starting at the foundation level. The poor performance in mathematics has been attributed to the fact that basic concepts are not being taught properly at the primary school level (Naidoo and Naidoo, 2010). This lack mathematics mastery at primary school level later on manifests at the secondary and tertiary levels, by way of poor results. Many intervention strategies have been implemented in addressing poor performance of mathematics in South Africa and the world over, like increasing the supply of qualified mathematics teachers (United States Aid (USAID), 2005: 4) and boosting parental involvement (Govender, 2007). In this study, efforts have been sought to motivate primary school learners in mathematics education by employing traditional items as tools of learning and teaching in rural primary schools (Nyota and Mapara, 2010: 189).

It is not circumstantial that this study targeted rural learners. Many times rural areas are ignored by mathematics movements and innovations (Bush, 2005: 2), and are historically disadvantaged (Singh, Mbokodo and Msila, 2010). The same sentiments were echoed by the Minister of Basic Education in her Budget Speech by saying, "One key area of focus is rural schools in our country, many of which are inadequately provided for in terms of infrastructure, as well as facilities ..." (Motshekga, 2009: 1). Furthermore, research has revealed that rural learners lag behind their urban counterparts academically (Naidoo and Naidoo, 2010). Masola (2010) noted how frustrating it always been reading about dismal failure rates in rural and township schools when the Grade 12 results are released. The 2010 Grade 12 national results statistics were even more illuminating on the severity of rural learners' performance, for instance, Mamaila Circuit located in central Bolobedu had an average pass rate of $45.8 \%$ against the national pass rate of $67.8 \%$ (DoE, 2011).The circumstances alluded to above ought to be a clarion call for researchers to focus more on rural areas in attempt to improve the quality of education in those places (DoE, 2005). Interestingly, rural areas, with their unique and diverse cultures, have high potential to disclose interesting and useful insights relating to the connection that exists between mathematics education and culture (Bush, 2005: 4). Learners should obviously benefit from what their respective cultures have on offer. Some cultural activities and plays, as shall be seen below, can be used to teach mathematics effectively at primary school (Bush, 2005: 4).

\section{Mathematics and games/plays}

It is notable the way mathematics textbooks are written often indicate bias towards non-rural learners. Textbook illustrations and problems predominantly highlight urban features like electric trains, investment annuities, escalators, and others. These by all intents, are aloof to the poor rural learners. The school curricula and teaching in most cases do not represent the local rural culture at all (Lipka and Adams, 2004). South Africa has even developed a science and mathematics curriculum based upon western trends and teaching is done mainly in foreign languages like English and/or Afrikaans (Muwanga-Zake, 2001). This cultural divide between school and community is a major factor causing the persistent gap between academic achievements, especially if we think of schools as part of the community they belong. By linking culture and the curriculum, teachers nurture the love for mathematics outside the classroom in order to assist what happens inside the classroom (Wyk, 2009). Play is a relevant tool to help achieve this connection if it can be linked to subject-based teaching in schools. In this research study the focus has been on cultural plays, in contrast to games. In plays, participants' objective may not be to determine a winner but merely to while away time (Nkopodi and Mosimege, 2009), while games are played competitively so as to determine a winner. In both games and plays, participants follow laid down rules, or amicably agree on how the rules can be amended. A striking advantage of indigenous games and plays is that they are cost-effective; they can be constructed without spending any money. If manipulated well, cultural activities and plays are an indigenous way of learning the school curricula and help to relate subjects like mathematics to the learners' everyday lives (TESSA, 
2010). Actually, one of the recommendations by the Department of Education to successful implementation of the curriculum was to discourage the use of textbooks, but encourage teachers to produce their own materials and teaching strategies (DoE, 2009: 9). Cultural practices whose rules are oftentimes unwritten but diligently adhered to, are fraught with skills such as: discovery of patterns, decision-making, counting and recognizing geometrical shapes. The role of educators is to elevate plays and cultural activities from being played for fun and pastime, but to relate them to specific mathematical concepts.

\section{Diverse Balobedu plays and cultural activities}

Children as youngsters have boundless energy for engaging in play, which educators can take advantage of, to enable learners to learn from the known to the unknown and from concrete to abstract. By using local cultural activities and plays in teaching and learning of mathematics, learners are motivated; more so as they see mathematics as a popular and historical activity. The mathematics practiced among identifiable cultural groups in the course of dealing with their environmental problems and activities was termed ethno-mathematics by Brazillian D'Ambrosio in the 1970s (Yusuf, Saidu, and Halliru, 2010: 37). With ethno-mathematics in mind, the researchers share what they saw as possible uses of some of the showcased Balobedu cultural activities and plays in a rural mathematics class. Below are some examples of cultural activities of the Balobedu:

- Mantlwane or mud house play in English, is where children use mud to bake cakes using different shapes and sizes of containers available. The cakes are dried in the sun and figuratively eaten thereafter. Sometimes roles of family members like father, mother, daughter and son are modelled to make the activity livelier. A multitude of mathematical skills are developed, for example, volume, measuring length and fostering identification of solid shapes during their modellings.

- Mosebe or bows-and-arrow is commonly used in hunting animals in rural areas; however they require knowledgeable use to be a successful hunter. A good angle of shooting and the correct direction towards target is a necessity. Such skills instill mathematical skills of angle size and a sense of direction in learners.

- Phate or weaved reed-mats from special grass can be effectively used to identify patterns, different kinds of shapes and colours. Learners should be in a position to identify the differently coloured plane shapes elaborately woven in the mats.

- Thai or riddles have been known to challenge learners' thinking and mental mathematics. For example, the riddle: "What is 8 divided in two parts?" provokes learners' cognitive thinking and visualization for them to get the answers: Vertically it is 3; horizontally it is 0 .

- Meruka or beadwork has been in practice amongst the Balobedu for ages, commonly practiced by women. Differently coloured- and sized-beads are used to make nice patterns and shapes. Learners would be able to quantify the beads by counting, as well identify them by size, colour and shape.

- Theneketša or free balancing of an open bucket full of water on the head performed mostly by rural women when they fetch water from a waterhole. The bucket is often balanced on the head without hands support, and sometimes these women put leaves on the open top of the bucket to minimise splashing of water. This procedure teaches learners balancing and problem-solving.

- Khitla or swimming, which is practiced in rivers and dams by rural children, intuitively teaches learners something about speed, depth and length. Direction is also learnt when learners have to figure out the correct direction of move from point A to point B in the pool.

- Matšhwaa and ditšhela are musical accessories in cultural dances and festivals. Matšhao are worn around the feet while ditšhela are hand-held devices which make distinctive sound when shaken rhythmically. These two help in the teaching of quantities and volume. Learners have to know the quantity of seeds that make appropriate sound.

- Molodi or whistling is practiced when herding cattle or when boys communicate one with another over a distance. Molodi teaches learners the notion of distance and speed, since in order for the other person to hear the whistle; he should be within a certain distance. Skills of mastering wind direction and the speed of sound are developed.

- Go thea dikhobe or fishing in rivers and dams is a feature of rural communities. Learners are exposed to ideas of depth and length when casting the fishing line to make a successful catch. Once the fish are caught, the aspects of size and colour are fostered when learners have to sort the fish. The floater requires the knowledge of weight, critical in the sense if floater is too heavy or too light, its behaviour on the water surface might be deceiving

- Godiša or herding cattle can be used to teach sets whereby children gather only those cattle which belongs to them. Concept of time is fostered when children have to know the exact times to take the livestock out of and into the kraal. 
- Morithi or shadow is very much useful for rural communities for judging time of the day. When the shadow hits a certain place, children know it is time do something like taking cattle out the kraal or go to the field.

- Selaga or mouse trap is a hunting technique for catching mice or other small animals. An average-sized flat stone is specially set at an angle in the path of mice to suddenly crush an animal when they bite the bait. Through selaga, children would learn about angles, mass of stone and length of sticks to be used.

- Maratetšo or fireplace is what rural folks use when they cook food on wood fire. In its simplest form, it is composed of three stones arranged in a triangular shape. This activity teaches learners shapes and balance since the pot has to be safely positioned on the stones without sliding or falling.

- Go aga rondavel or building a round hut exposes children to the notion of circle, circumference and area. Usually, when the circumference is marked, people fasten a wooden peg on the ground and by tying a rope of appropriate radius, they trace out a circle. This also teaches children drawing a circle using a pair of compasses.

- Go fefera or winnowing is a process where women separate impurities from grain by pouring the grain mixture from a raised sefo into a receiving container in the presence of moderate wind. This teaches children about height, wind speed and weight.

- Boys use direkere or catapults when they play shooting things, especially birds. This will teach them about wind direction, speed, distance and time so as to aim at the object (Chikodzi and Nyota, 2010).

- Similarly used by boys is seragamabje or slingshot, such as one used by biblical David on Goliath. By this, children learn about direction, speed and distance in order to take a sharp aim.

- Bopa or clay toys is an activity which see children designing different solids, animals and other things from wet clay. The objects are dried in the sun to make them firm and permanently hard. Children learn the skill of volume, shapes, measurement and patterns.

Besides cultural activities, there also games and plays that are played by youngsters which do have the potential to aid the teaching and learning of mathematics in rural schools. The different types of games and plays are given below:

- Kgathi or rope skipping is often played by children. By this learners are taught counting skills, balancing and speed since they must adjust to the speed of the revolving rope. As they skip, they will be counting, and sometimes compete to see who would skip the highest count.

- Kites are made from plastic paper fastened on grass stalks in a diamond-like shape. A long rope is tied near the centre to pull the kite. To add stability, tails are attached at the bottom and sides corners. From this game, children learn about the shape of kite and speed of the wind which would in turn determine the ascendancy of the kite. Children also figure out the mass which would make the kite airborne.

- In a game of tsheretshere, children throw a flat stone which they push with one from one box to another while balancing on one leg. Sometimes instead of rectangular boxes they use circles, which help learners develop the sense of shapes. The counting system is developed every time a player plays since they have to remember where they ended and where to start the next time. The concepts of mass, weight and balancing are also perfected in the process.

- Tug-of-war is played by putting a distinct marker in the middle of a long rope and assigning two groups of equal numbers of children equidistantly on either side of the marker. The two groups pull the rope to their side strongly so as not to be outdone by their opponents. The group pulled would follow the other and lose. This game can be used in the teaching of mass and weight since the side with heavies is more inclined to win.

- The game of moruba consists of four rows of eight holes which are dug into the earth which are initially filled pebble counters called mathlapa. Each player uses only his side of the board, which consists of two rows. At his turn, a player takes the contents of one of his holes, which must contain at least two stones and distributes them one by one counterclockwise into consecutive holes on his side. If the last stone falls into a non-empty hole, its contents are distributed in another lap in the same direction. The move ends when the last stone falls into an empty hole. If the last stone is put into an empty hole of the inner row and the opposite hole of the opponent contains stones, these enemy stones are 'killed' (tlaba). Additionally, the stones of the outer hole directly behind it are 'captured' (tlola) and the contents of any other enemy hole. The killed or captured stones of the opponent are removed from the board. When a player has only singletons, he is permitted to move them, but only in empty holes. The player who still has counters at the end of the game is declared the winner, while the other player who has no stones left, has lost (TESSA, 2010). Sets, counting and addition are learnt during the play of game. 
- Morabarala game is played by two people each with twelve identical objects, different from the opponent's. Players strive to block the opponent from forming a row, diagonal or column of three stones. If such a row is formed, an opponent's strategically placed piece is taken off the game. This goes on until one player's objects are finished. Sets, counting, symmetry, geometrical shapes, ratio, proportion and logical reasoning are some of the skills duly developed through the playing this game.

- In the game of dinketo, stones are placed in a hole or a circle if it is on a hard surface. The first player throws a stone in the air and promptly scoops all the stones out of the hole before catching the stone again. The player then painstakingly scoops the stones back into the hole, one at a time. During the second round, two stones are returned into hole and so on until the player scoops all the stones back into the hole. This game teaches children to add, subtract and group stones into sets of differing numbers.

- The game senthee or hit-me game is played using a ball to hit those inside the pitch. Those inside skillfully dodge the ball at the same time arranging a hip of flat stones or bricks. Those hit by the ball leave the pitch one by one until the last one is hit and they change sides. Children are taught the concepts of speed and direction since the ball must be fired at a certain speed in the direction of the target.

- Koloi yaterata or wire cars are made by young boys as toys, and which requires great skill. This teaches learners about measurement, length, symmetry and shapes.

- A see-saw is made from a wood-pole positioned on top of a pivot so that it is balancing on its own. Two children or sometimes more sit on either end of the pole and enjoy moving up and down. If the children are of the same weight, they hang in balance in mid-air. Children are taught weight and balance for they it does not take them long to realise that those who are heavier tip the pole down.

- Rolling a bicycle rim using a wire or a stick helps children to master the skills of balance, direction and force.

- Tšhaba legotlo katsi yaloma or cat-and-mouse game is played by two opposing groups of learners. The first group has to run and catch each of the elusive opponent group members. Only the elusive and agile members survive the chase and become winners. The game teaches learners speed and counting since they have to make a count up to a certain amount before and after a chase.

\section{Conclusion}

The Balobedu children are among the unfortunate tribal groups in South Africa who do not enjoy the privilege of reading and writing in their mother tongue, despite the fact that they have a unique culture with a language of their own. Embracing local cultural activities and plays in the teaching and learning of mathematics accords the Balobedu children an opportunity to participate in learning in their own language. The subject of mathematics has been a concern to researchers in South Africa for two reasons; its performance has been consistently low for the past three years at matric level (DoE, 2011, Holley, 2011) and the number of learners who enroll for mathematics is nose-diving every year (Parker, 2011; National Professional Teachers' Organisation of South Africa (NAPTOSA), 2011). Needless to say, mathematics, together with other natural Sciences, is a gateway subject (NAPTOSA, 2011; Hamlyn, 2010) highly sought after to fuel the scientific and economic engines of any nation (Bush, 2005; Wolmarans, Smit, Collier-Reed and Leather, 2010). Primary school performance is equally disappointing, as indicated by a research conducted in 2004 by the Department of Education, which reported that achievement rates for Grade 6 learners were 38\% in English, 27\% in mathematics and 41\% in Natural Science (DoE, 2008). More so, learners from African and public schools have the lowest average scores (Reddy, 2006). Hence, intervention strategies for improving mathematics performance should, by all intents, start at the foundation phase of learning in those places considered disadvantaged. A number of cultural activities have been highlighted as well divers plays and games, most of which are not restricted to a specific cultural group, hence usable even in a multicultural educational setting (Nkopodi and Mosimege, 2009). Some teachers in rural areas who have attempted to inject some of the highlighted cultural activities and plays in their lessons have reported that the practice indeed increased learners' participation during mathematics lessons (Chikodzi and Nyota, 2010) and promoted spontaneous interaction amongst learners (Nkopodi and Mosimege, 2009).

\section{References}

Bansilal, S., James, A., \& Naidoo, M. (2010). Whose voice matters? Learners. South African Journal of Education, 30, $153-165$.

Bush, W.S. (2003). Bridging the gap between culture and Mathematics: The Appalachian perspective. Paper originally presented at the Annual Meeting of the American association of Colleges of Teacher Education, New Orleans. 
Bush, W.S. (2005). Improving Research in Mathematics Learning and Teaching in Rural Contexts. Journal of Research in Rural Education, 20 (8), 1 - 11.

Chikodzi, I., \& Nyota, S. (2010). The Interplay of Culture and Mathematics: The Rural Shona Classroom. The Journal of Pan African Studies, 3 (10), 4 - 15.

de Klerk, V. (2006). Code switching, Borrowing and Mixing in a Corpus of Xhosa English. The International Journal of Bilingual Education and Bilingualism, 9 (5), 597 - 614. http://dx.doi.org/10.2167/beb382.0

Department of Education (DoE). (2003). The development of indigenous African languages as mediums of instruction in higher education. Pretoria: Government Printers.

DoE. (2005). Report of the Ministerial committee on rural education: A new vision for rural schooling. Pretoria: Government Printers.

DoE. (2008). Education for All Country Report: South Africa. Pretoria: Government Printers.

DoE. (2009). Report of the Task Team for the Review of the Implementation of the National Curriculum Statement. Pretoria: Government Printers.

DoE. (2011). Report on the National Senior Certificate Examination Results. Pretoria: Government Printers.

Erasmus, M. (2011, 13 - 15 July). Limpopo learners perform dismally in the Department's Annual National Assessment. The Capricorn Voice, p.4.

Fleisch, B., Shindler, J., \& Perry H. (2010). Who is out of school? Evidence from the Community Survey 2007, South Africa International Journal of Educational Development, 4 (4), 123 - 134.

Govender, V. G. (2007). A Multiple case study of parent Involvement with Grade 8 Learners of Mathematics. (Unpublished Doctoral Thesis). Nelson Mandela Metropolitan University, Port Elizabeth, South Africa.

Hamlyn, M. (2010). Motshekga most unhappy with poor matric results. [Online] Available: http://mg.co.za/article/2010-01-07-motshekga-most-unhappy-with-poor-matric-results (May 02, 2011)

Holley, L. (2011). School results worse than expected. [Online] Available; http://www.ecr.co.za/kagiso/content/en/east-coast-radio/east-coast-radio-mobile news?oid=1267070\&sn= Mobile+ news+detail\&pid=171901 (June 30, 2011)

Howie, S.J. (2003). Language and other background factors affecting secondary school pupils' performance in Mathematics in South Africa. African Journal of Research in SMT Education, 7 (7), 1 - 20.

Keet, J. (2010). Matric results a wake-up call for South Africa. [Online] Available: http://mg.co.za/article/2010-01-07-matric-results-a-wakeup-call-for-sa (May, 02, 2011)

Lipka, J., \& Adams, B. (2004). Culturally-based Mathematics education as a way to improve Alaska Native students' Math Performance. Appalachian Collaborative Center for Learning, Assessment, and Instruction in Mathematics (ACCLAIM): Working Paper no. 20

Makgato, M., \& Mji, A. (2006). Factors associated with high school learners' poor performance: a spotlight on Mathematics and physical science. South African Journal of Education, 26 (2), 252 - 266.

Manuel, T. (2011). SA has failed to deliver to the poor. [Online] Available: http://mg.co.za/article/2011-03-16-manuel-sa-has-failed-to-deliver-the-poor (May 02, 2011)

Masola, A. (2010). Classrooms in South Africa are failing our children. [Online] Available: http://www.thoughtleader.co.za/mandelarhodesscholars/2010/06/05/classrooms-in-south-africa arefailing-our-children/ (June 05, 2010)

Mosimege, M. (2003). Indigenous Mathematical Knowledge at South African Cultural Villages: Opportunities for Integration in Mathematics Classrooms. [Online] Available: http://math.unipa.it/ grim/21_project/21_charlotte_MosimegePaperEdit.pdf (May 03, 2011)

Motshekga, A. (2009). Basic Education: Minister's Budget Speech. Pretoria: Parliamentary Monitoring Group.

Muwanga-Zake, J.W.F. (2001). Is Science Education in a crisis? Some of the problems in South Africa. [Online] Available: http://www.scienceinafrica.co.za/scicrisis.htm (April 25, 2011)

Naidoo, N., \& Naidoo, R. (2010). ICT and Mathematics in a semi-rural classroom: A case study in the learning of volume. National Rural School Leadership Journal April, 1 (1), 94 - 106.

National Professional Teachers' Organisation of South Africa (NAPTOSA). (2011). Zuma, unions laud matric results. [Online] Available: http://mg.co.za/article/2011-01-06-zuma-unions-laud-matric-results (May 03, 2011) 
Nkopodi, N., \& Mosimege, M. (2009). Incorporating the indigenous game of morabaraba in the learning of Mathematics. South African Journal of Education, 29, 377 - 392.

Nyota, S., \& Mapara, J. (2008). Shona Traditional children' games and play: Songs as Indigenous Ways of knowing. The Journal of Pan African Studies, 2 (4), 189 - 202.

Parker, F. (2011). No idea of the quality of Matric passes. [Online] Available: http://mg.co.za/article/2011-01-06-no-idea-of-the-quality-matric-passes (May 02, 2011)

Reddy, V. (2006). The state of Mathematics and Science Education: Schools are not equal. [Online] Available: http://www.hsrcpress.ac.za (May 02, 2011)

Rice, M. (2010). Why we need new colleges of education. [Online] Available: http://mg.co.za/article/2010-11-05-why-we-need-new-colleges-of-education (May, 02, 2011)

Singh, P., Mbokodo, S.M., \& Msila, V.T. (2010). Black parental involvement in Education. South African Journal of Education, 24 (4), 301- 307.

Teaching Education in Sub-Saharan Africa (TESSA). (2010). Investigating Number patterns: Learning through Games. [Online] Available: http://www.tessaafrica.net (May 03, 2011)

United States Aid (USAID). (2005). Africa Education Iniative - South African case study. [Online] Available: http://pdf.usaid.gov/pdf_docs/PNADG232.pdf (May 13, 2011)

Waldner, M. (2011, July 3). Better off the Bantu Education? Numeracy still in crisis but it's not as bad as during Apartheid. The City Press, p.5.

Wolmarans, N., Smit, R., Collier-Reed, B., \& Leather, H. (2010). Addressing concerns with the NSC: An analysis of first-year student performance in Mathematics and Physics. Paper presented at the 18th Conference of the Southern African Association for Research in Mathematics, Science and Technology Education, Kwazulu-Natal, 274-284.

Wyk, S. (2009). Mathematics with a Vision. [Online] Available: from http://mg.co.za/article/2008-09-09-maths-with-a-mission\#disqus_thread (May 02, 2011)

Yusuf, M.W., Saidi, I., \& Halliru, A. (2010). Ethnomathematics (A Mathematical game in the Hausa culture). International Journal of Mathematical Science Education, 3 (1), 36-42. 